\title{
Searching for dust
}

\section{Jason Neff and his team searched the depths of frigid alpine lakes for clues on dustiness in the western United States.}

What was the objective of the work? We began this study after hearing many stories about recent dust deposition from locals in the San Juan Mountains of Colorado in the US, and after seeing some of the local dust storms ourselves. These events quickly made us wonder to what degree they are a natural phenomenon or a result of humans changing the environment. Lake sediments seemed like a good way to address that question, but at the start we didn't know if we could distinguish dust in these sediments, nor did we have a clear plan to evaluate changes in deposition rates. Because our work was supported by a foundation without a specific goal in mind, we were able to let our curiosity guide our science and figure out the methods as we worked. As it happened, the data were far clearer than we could have hoped, and the story quickly emerged from these sediment records.

\section{Why did you choose this particular location for the fieldwork? We started work in the San Juan} Mountains because they provide a diversity of geologic and geochemical settings. We began to appreciate the importance of dust because our strontium isotope studies of soils suggested that there was considerable non-local soil material in the high elevation basins. As luck would have it, we stumbled across alpine lakes that ended up being perfect dust collectors - because of their location in relation to the deserts of the western US, their high elevations and undisturbed surroundings.

\section{Did you encounter any difficulties,}

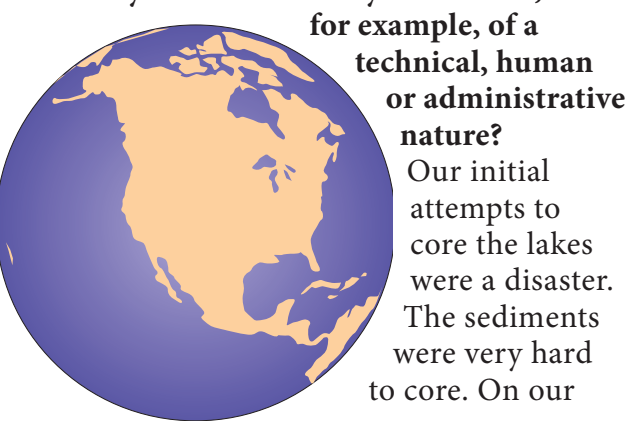

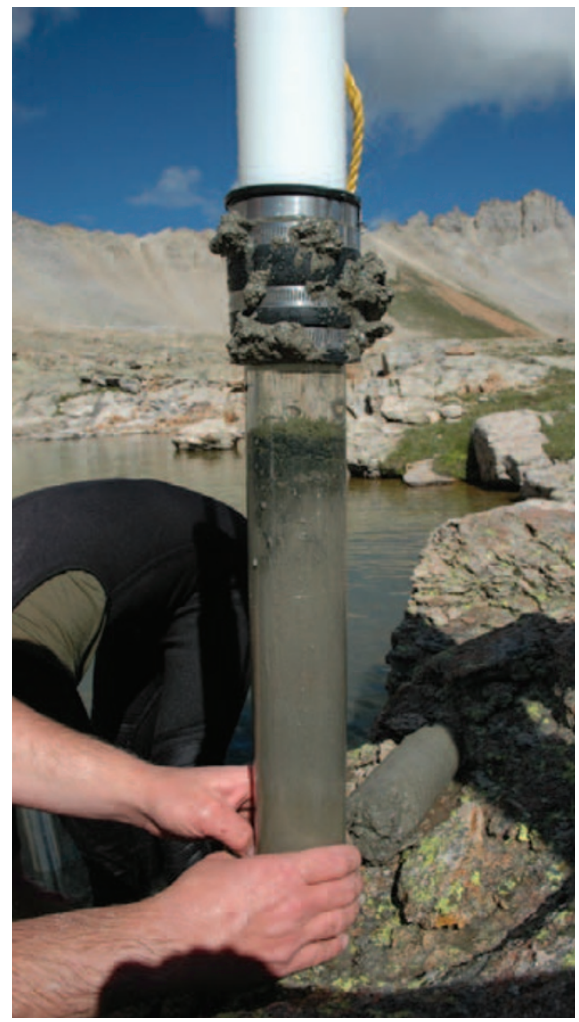

Lake dust. Sediments containing dust are recovered.

first try it was $2{ }^{\circ} \mathrm{C}$ with alternating rain and snow showers and we had far too few warm clothes. Later, we tried earlyseason coring from rafts anchored to ice on the lakes, but after several days of fruitless attempts with very cold hands, we gave up. After studying detailed maps, we made a plan to take trucks relatively close to some high-elevation lakes during the summer. The four wheel drive roads that took us to our sites were long and dangerous. One of the worst parts was at a narrow section of road, precariously cut into a slope and with several hundred metres of exposure below. The drive became much more complicated when we encountered a jeep coming from the other direction and had to reverse for a hundred metres with no room for error. After all this, we finally managed to obtain the cores that are used in this publication.

Did you have any encounters with dangerous animals?

There were some dangerous looking marmots that appeared to be waiting for the opportunity to steal our lunch bags.

\section{What was the highlight of the expedition?}

Our lake sites are at the very top of beautiful alpine basins in the San Juan Mountains. After spending time in cold water, there's nothing like sitting in the sun at 3,500 m altitude. In the end, however, the highlight was realizing that our collection efforts worked and that we found a record of dust deposition that shows thousands of years of change in the western US.

Did you learn anything new about yourself or your team members? Working in high alpine settings can be great fun or completely miserable - often both on the same day. We're very fortunate to have a group of people who enjoy warm and sunny days but are at their best when they are cold, wet and shivering uncontrollably.

Did the trip give you any ideas for future research projects?

Yes! We've very excited to continue this work in sites across the western US and elsewhere. We would love to develop collaborations with researchers in other countries where large recent changes in land use have occurred. One of our goals is to determine whether our findings are unique to the western US or whether these changes have occurred more broadly. We are also currently exploring the biogeochemical implications of this increase in dust deposition, as certain nutrients and pollutants appear to be associated with modern dust.

This is the Backstory to work by Jason Neff and colleagues, published on page 189 of this issue. 